\author{
Kees H. Polderman \\ David K. Menon \\ Armand R. J. Girbes
}

\section{Treating intracranial hypertension in traumatic brain injury: keep it cool!}

Accepted: 8 March 2008

Published online: 8 May 2008

(C) The Author(s) 2008

An author's reply to this comment is available at:

doi:10.1007/s00134-008-1133-5.

Stocchetti et al. [1] have reported their experience with currently available "second tier" therapeutic options for the treatment of refractory intracranial hypertension in patients with traumatic brain injury (TBI) in three Italian neurotrauma centres. The authors discuss three options to control intracranial pressure: profound hyperventilation, barbiturate coma and decompressive craniectomy. These options were used alone or in combination.

We were surprised that fever management and mild therapeutic hypothermia were not discussed or even mentioned (other than as a potential source of complications) in this article. Various research groups (including one of the centres involved in the present study) have reported that development of fever following TBI is closely linked to intracranial hypertension [2-5]; this would suggest that fever management should be one of the first steps in controlling intracranial hypertension, but this is not mentioned in the article of Stocchetti et al.

Further, it has been conclusively demonstrated (in 14 studies enrolling $>1,500$ patients) that ICP can be significantly decreased by induction of mild hypothermia [5-10]. Moreover, although the results from studies using hypothermia to improve outcome following severe TBI have been conflicting, the preponderance of evidence strongly suggests that prolonged (3-5 days) cooling can significantly improve neurological outcome in patients with intracranial hypertension [5-10]. None of the therapeutic options discussed by Stocchetti et al. has so far been shown to improve neurological outcome; studies using barbiturate coma [11-13] or hyperventilation [14$15]$ in patients with refractory intracranial hypertension reported decreases in ICP but no benefits in outcome. Decompressive craniotomy has shown promise in one small study in 27 paediatric patients [16], but has not yet been well studied in adults [17]. Two RCTs addressing this issue are currently in process [18-19].

Hypothermia does not decrease cerebral blood flow without reducing metabolism and oxygen demand, as is the case with hyperventilation [20], and, when used judiciously, tends to cause no hypotension and less myocardial dysfunction than barbiturates. The evidence regarding improved neurological outcome in TBI associated with hypothermia can certainly be debated; but the evidence is (at the very least!) as strong and as favourable as for barbiturates and hyperventilation. Therefore, induced hypothermia should be regarded as one of the "second tier" therapies in refractory intracranial hypertension, and as such deserves to be mentioned as a feasible option in the otherwise excellent discussion by Stocchetti et al.

Open Access This article is distributed under the terms of the Creative Commons Attribution Noncommercial License which permits any noncommercial use, distribution, and reproduction in any medium, provided the original author(s) and source are credited.

\section{References}

1. Stocchetti N, Zanaboni C, Colombo A, Citerio G, Beretta L, Ghisoni L, Zanier ER, Canavesi K (2008) Refractory intracranial hypertension and "secondtier" therapies in traumatic brain injury. Intensive Care Med 34:461-467
2. Rossi S, Zanier ER, Mauri I, Columbo A, Stocchetti N (2001) Brain temperature, body core temperature, and intracranial pressure in acute cerebral damage. J Neurol Neurosurg Psychiatry 71:448-454

3. Soukup J, Zauner A, Doppenberg EM, Menzel M, Gilman C, Young HF, Bullock R (2002) The importance of brain temperature in patients after severe head injury: relationship to intracranial pressure, cerebral perfusion pressure, cerebral blood flow, and outcome. J Neurotrauma 19:559-571

4. Diringer MN, Reaven NL, Funk SE, Uman GC (2004) Elevated body temperature independently contributes to increased length of stay in neurologic intensive care unit patients. Crit Care Med 32:1611-1612

5. Polderman KH (2008) Induced hypothermia and fever control for prevention and treatment of neurological injuries. Lancet 371 (in press)

6. Polderman KH (2004) Therapeutic hypothermia in the intensive care unit: problems, pitfalls and opportunities (review). Part 1: indications and evidence. Intensive Care Med 30:556575

7. Polderman KH, Ely EW, Badr AE, Girbes AR (2003) Induced hypothermia in traumatic brain injury: considering the conflicting results of meta-analyses and moving forward. Intensive Care Med 29:1637-1644

8. Polderman KH, Tjong Tjin Joe R, Peerdeman SM, Vandertop WP, Girbes ARJ (2002) Effects of artificially induced hypothermia on intracranial pressure and outcome in patients with severe traumatic head injury. Intensive Care Med 28:1563-1567

9. McIntyre LA, Fergusson DA, Hebert PC, Moher D, Hutchison JS (2003) Prolonged therapeutic hypothermia after traumatic brain injury in adults: a systematic review. JAMA 289:29922999

10. Brain Trauma Foundation, American Association of Neurological Surgeons, Congress of Neurological Surgeons, Joint Section on Neurotrauma, Critical Care AANS/CNS (2007) Guidelines for the management of severe traumatic brain injury. III. Prophylactic hypothermia. J Neurotrauma 24(Suppl 1):S21-S25

11. Roberts I (2000) Barbiturates for acute traumatic brain injury. Cochrane Database Syst Rev 2:CD000033 
12. Eisenberg HM, Frankowski RF, Contant CF, Marshall LF, Walker MD (1988) High dose barbiturate control of elevated intracranial pressure in patients with severe head injury. J Neurosurg 69:15-23

13. Bohn DJ, Swan P, Sides C, Hoffman H (1989) High-dose barbiturate therapy in the management of severe paediatric head injury: a randomised controlled trial. Crit Care Med S118:17 [abstract]

14. Brain Trauma Foundation, American Association of Neurological Surgeons, Congress of Neurological Surgeons, Joint Section on Neurotrauma and Critical Care, AANS/CNS (2007) Guidelines for the management of severe traumatic brain injury. Guidelines for the management of severe traumatic brain injury. XIV. Hyperventilation. J Neurotrauma 24(Suppl 1):S87-S90

15. Muizelaar JP, Marmarou A, Ward JD, Kontos HA, Choi SC, Becker DP, Gruemer H, Young HF (1991) Adverse effects of prolonged hyperventilation in patients with severe head injury: a randomized clinical trial. J Neurosurg 75:731-739
16. Taylor A, Butt W, Rosenfeld J, Shann F, Ditchfield M, Lewis E, Klug G, Wallace D, Henning R, Tibballs J (2001) A randomized trial of very early decompressive craniectomy in children with traumatic brain injury and sustained intracranial hypertension. Childs Nerv Syst 17:154-162

17. Sahuquillo J, Arikan F (2006) Decompressive craniectomy for the treatment of refractory high intracranial pressure in traumatic brain injury. Cochrane Database Syst Rev 1:CD003983

18. http://www.controlled-trials.com/ ISRCTN66202560/RESCUEicp

19. http://clinicaltrials.gov/ct2/show/ NCT00155987

20. Nortje J, Coles JP, Timofeev I, Fryer TD, Aigbirhio FI, Smielewski P, Outtrim JG, Chatfield DA, Pickard JD, Hutchinson PJ, Gupta AK, Menon DK (2008) Effect of hyperoxia on regional oxygenation and metabolism after severe traumatic brain injury: preliminary findings. Crit Care Med $36: 273-281$
K. H. Polderman $(\bowtie)$

Department of Intensive Care, Utrecht University Medical Center, Q 04.4.60, P.O. Box 85500, 3508 GA Utrecht, The Netherlands e-mail: k.polderman@umcutrecht.nl; k.polderman@tip.nl

Tel.: +31-88-7553261

Fax: +31-88-7553220

\section{K. Menon}

Division of Anaesthesia, Addenbrooke's Hospital, University of Cambridge, Cambridge CB2 2QQ, UK

\section{A. R. J. Girbes}

Department of Intensive Care, VU

University Medical Center, P.O. Box 7057, 1007 MB Amsterdam, The Netherlands e-mail: arj.girbes@vumc.nl 